\section{International Scientific Journal Theoretical \& Applied Science}

\author{
p-ISSN: 2308-4944 (print) e-ISSN: 2409-0085 (online) \\ Year: 2017 Issue: 09 Volume: 53
}

Published: $30.09 .2017 \quad \underline{\text { http://T-Science.org }}$
Vladimir Nikolaevich Medvedev

The Teacher Department of Navigation,

The Engineer-mechanic,

State Maritime University Admiral Ushakov, Russia, medvedevsail@gmail.com

SECTION 21. Pedagogy. Psychology. Innovation in Education

\title{
YACHTING - CONDITIONS OF FORMING OF SPECIAL TECHNOLOGY SKILLS OF STUDENTS OF SEA HIGHER EDUCATIONAL INSTITUTIONS
}

\begin{abstract}
The basic principles of creation of educational system of the students doing yachting are considered; the increasing role of occupations of students yachting in the system of sea professional education and insufficient readiness of their practical organizations reveals; conditions of forming of special technology skills of students and insufficient use of educational opportunities of occupations are analyzed by yachting; need of development of professional and technology skills of students and insufficient readiness of scientific and methodical providing bases of a practical training is shown yachting.

Key words: forming of the personality, students, yachting, professional education, practical organization, naval fleet.

Language: Russian

Citation: Medvedev VN (2017) YACHTING - CONDITIONS OF FORMING OF SPECIAL TECHNOLOGY SKILLS OF STUDENTS OF SEA HIGHER EDUCATIONAL INSTITUTIONS. ISJ Theoretical \& Applied Science, 09 (53): 171-176.

Soi: http://s-o-i.org/1.1/TAS-09-53-26 Doi: crossef https://dx.doi.org/10.15863/TAS.2017.09.53.26

УДК 372.851

\section{ЯХТИНГ - УСЛОВИЯ ФОРМИРОВАНИЯ СПЕЦИАЛЬНЫХ ТЕХНОЛОГИЧЕСКИХ НАВЫКОВ СТУДЕНТОВ МОРСКИХ ВЫСШИХ УЧЕБНЫХ ЗАВЕДЕНИЙ}

Аннотация: Рассмотрены основные принципы построения воспитательной системы студентов, занимающихся яхтингом; раскрывается возрастающая роль занятий студентов яхтингом в системе морского профессионального образования и недостаточная разработанность их практических организаций; анализируются условия формирования специальных технологических навыков студентов и недостаточное использовании воспитательных возможностей занятий яхтингом; показывается необходимость развития профессионально-технологических навыков студентов и недостаточная разработанность научно-методического обеспечения основ практических занятий яхтингом.

Ключевые слова: формирование личности, студенты, яхтинг, профессиональное образование, практическая организация, морской флот.
\end{abstract}

\section{Introduction}

Обществу нужны специалисты, готовые к самостоятельному включению в в производственные процессы, способные практически решать встающие перед ними жизненные и профессиональные задачи. А это во многом зависит не только от полученных знаний, умений, навыков, но и от дополнительных качеств, для обозначения которых в настоящее время и употребляются понятия «компетенция» и «компетентность», более соответствующие требованиям, предъявляемым в реальных условиях работодателями. В учебных заведениях реализуется традиционная модель обучения, основанная на знаниевой парадигме образования, переход на компетентностный подход в системе образования требует обновления содержательно-технологического обеспечения учебно-воспитательного процесса. [14]

Работодателям необходимы выпускники, готовые действовать самостоятельно в рамках 
своей компетенции в соответствии с требованиями производственного процесса. Значительно возрастает роль образовательных учреждений, которые готовят конкурентоспособного специалиста, обладающего личностными и профессиональными качествами, которые могут решать различные задачи во всех видах деятельности и отвечать за их решение. Современное образование должно быть направлено на формирование личности, способной адаптироваться к быстро меняющимся экономическим, технологическим, социальным и информационным реалиям окружающего мира. Ha первый план выходит проблема формирования технологической компетентности личности, обеспечивающая успешную деятельность в производственном процессе. В этой связи ориентация студентов на овладение производственно-технологической

компетентностью приобретает профессиональноценностный смысл.

Значительное место в формировании данной компетентности в учебном процессе отводится циклу общепрофессиональных дисциплин. Как показывает практика, студенты высших учебных заведений испытывают определенные затруднения в актуализации знаний о сущности производственнотехнологической деятельности в процессе освоения дисциплин данного цикла. Это связано с тем, что осуществляемые сегодня реформы не затрагивают сущностные аспекты профессиональной подготовки студентов технического вуза. В результате усложняется адаптация молодых специалистов к условиям производства.

Формирование

востребованных современным рынком труда специальных технологических навыков у студентов морских высших учебных заведений является актуальной образовательной задачей, что подтверждается федеральным государственным образовательным стандартом (ФГОС). Однако анализ реальной ситуации в образовательной практики морских высших учебных заведений показывает, что в рамках занятий студенческим яхтингом сложились предпосылки для разработки вопросов условий формирования технологических компетенций будущих специалистов морской отрасли на основе задачного обучения этому виду деятельности.

Формирование специальных технологических навыков студента - процесс, в ходе которого он приобретает профессионально важные знания, навыки и качества. Условием успешного формирования специальных технологических навыков студентов морских высших учебных заведений является внедрение в процесс изучения дисциплин профессиональных циклов занятий яхтингом. В рамках этих занятий со студентами необходимо практиковать задачное обучение, способное обеспечить целенаправленное, пошаговое приобретение специальных технологических навыков. Такая форма проведения занятий представляет собой поэтапную организацию постановки учебных задач и упражнений преподавателем; выбор способов их решения, диагностики и оценки полученных результатов студентами.

Преподаватель на яхте - капитан, иначе шкипер, а вместе со студентами - экипаж. Задача преподавателя - создание на борту учебной яхты обстановки для наиболее интенсивного проявления и совершенствования технологических навыков у экипажа. Можно выделить три группы психологических условий успешного формирования технологической деятельности студента: со стороны его личности; со стороны преподавателей, руководителей; со стороны их совместной деятельности. Технологические навыки студента во время занятий яхтингом формирует сумма влияний, которым он подвергается: организация деятельности шкипером (распределение обязанностей), занятия по различным задачам технологических компетентностей, личный пример преподавателя, руководителя, отношение к выполнению поставленных задач со стороны самого студента. Будучи взаимно связанными, все качества формируются в органическом единстве.

Непрерывное самообразование, повышение профессиональной компетентности студентов, независимо от уровня получаемого образования, выступают как метод расширения их технологических навыков. Для общества непрерывное

совершенствование профессиональной

компетентности студентов

становится механизмом воспроизводства и развития рабочей силы, также ориентированной на непрерывное расширение «горизонтали» своей квалификации, возможности которой безграничны. [9,1].

Несмотря на достаточно широкий спектр исследований, посвященных поиску наиболее эффективных способов условий формирования специальных технологических навыков студентов морских высших учебных заведений, ученые не рассматривали в качестве одного из них студенческий яхтинг как вид факультативной деятельности в вузе.

\section{Materials and Methods}

Яхтинг можно рассматривать как важный психолого-педагогический ресурс для приобретения студентами определенного жизненного и практического опыта, создания 
инновационно-творческой

среды, усиления мотивации, овладения способами

образовательной профессиональной самоуправления и самообразования, а также воспитания профессионально-технологических качеств, которые, в свою очередь способствуют развитию мотивации углубления знаний в профессиональной деятельности.

Сформулируем проблему в виде следующего вопроса, при каких психологопедагогических факторах яхтинг может создать условия формирования специальных технологических навыков студентов морских высших учебных заведений?

Актуальность проблемы определила тему исследования «яхтинг - условия формирования специальных технологических навыков студентов морских высших учебных заведений».

Занятия яхтингом в вузе могут быть эффективным ресурсом формирования специальных технологических навыков студентов при условии:

психологопедагогической подготовленности преподавателей (шкиперов);

отбором средств и методов педагогического воздействия на студентов;

- личностным отношением студентов к познавательной деятельности, их собственной активностью;

- насыщение программы подготовки студентов вузов дополнительными занятиями яхтингом;

- изменения характера содержания и организации учебных практик студентов плавательных специальностей морских вузов;

- поощрение студентов занимающихся яхтингом, принимающих участие в регатах различного уровня, занимающихся подготовкой яхт к навигации во время межсезонного периода.

Необходимо так построить учебновоспитательный процесс в вузе, который способствовал бы актуализации студентов к их профессиональной деятельности, развитию личности и побуждал их к профессиональному саморазвитию на этапе начального приобретения профессиональных навыков. [6,7].

Актуализация внутреннего мира студентов, определение ими личностной значимости и ценности занятий яхтингом стало возможным благодаря активным методам обучения. Дискуссии, круглые столы, тренинги, социальное проектирование способствовали активизации учебного процесса. Участие студентов в регатах, крейсерских походах, реализации социальнозначимых проектов, подготовке и проведении мероприятий морской направленности дало возможность студентам приобрести специальные технологические навыки. Эти мероприятия позволили студентам повысить профессиональный и личностный опыт работы с различными категориями и типами людей, испытать технологии будущей работы [2,4].

Модель занятий студенческим яхтингом будет способствовать развитию профессиональной деятельности будущих специалистов как плавательных, так и гуманитарных специальностей, стимулировать актуализацию их технологических навыков при соблюдении совокупности педагогических условий:

- содержания видов деятельности на палубе яхты осуществляется в соответствии с показателями готовности будущего специалиста к выполнению производственно-технологической деятельности (готовность: К проектированию технологических процессов и производства; к организации и осуществлению производственнотехнологической и инновационной деятельности; к рефлексии, самоконтролю и коррекции результатов производственно-технологической деятельности);

- формирование данной компетентности происходит по следующим этапам: информационный (решение задач на выделение искомых данных, уточнение формулировок задач, установление противоречий), процессуальнообучающий (соотнесение имеющихся знаний и готовности решать задачи; использование логико-поисковых задач, ориентированных на производственную деятельность инженера), деятельностный (умения выдвигать гипотезу, находить принципы решения, соотносить их с условиями задач, поставленных производственными проблемами и ситуациями) и обеспечивается применением многоуровневых задач и заданий профессиональной направленности;

- создание профессиональнообразовательной среды, способствующей развитию технологических навыков будущего специалиста, доминирующих в производственнотехнологической деятельности, достигается путем обогащения педагогических форм производственно-технологическими задачами, характерными для общепрофессиональных дисциплин (изучение базы инженерной деятельности, принципов производственных процессов, теоретических основ устройства и работы оборудования).

Разработана система критериев, с помощью которых можно оценить положительную динамику изменений у студентов, занимающихся под парусами, убедиться в эффективности модели занятий студенческим яхтингом. 


\section{Conclusion}

Выполненное исследование вносит определенный вклад в изучение проблемы формирования у студентов морских вузов специальных технологических навыков, одним из способов достижения которой являются занятия яхтингом.

Анализ психологических трудов помог выявить внутренние механизмы процесса личностного развития студентов - они наиболее адекватны у занимающихся яхтингом: интериоризация, доминанта, самопознание и рефлексия. [8,3].

На основе философских и психологопедагогических исследований разработана модель занятий яхтингом в вузе. Данная модель учитывает совокупность факторов, условий, предпосылок, закономерностей и принципов профессионального развития будущих студентов - специалистов, а также выявляет критерии и эмпирические показатели его эффективности. Как показало исследование, успешность позитивного влияния яхтинга на формирование технологических навыков у студентов зависит от следующих факторов: взаимодействия преподавателей и студентов; активной включенности студентов и преподавателей в яхтинг; приобретаемого студентами позитивного субъектного опыта. [5,10].

Формирование технологических навыков возможно осуществлять эффективно при реализации компетентностного подхода предусматривающего:

организацию поэтапного формирования производственно-технологической

компетентности от информационного и процессуально-обучающего

до деятельностного посредством применения многоуровневых задач и заданий профессиональной направленности; создание профессиональнообразовательной среды, способствующей развитию качеств личности будущего специалиста, доминирующих в производственнотехнологической деятельности, путем обогащения педагогических форм задачами производственно-технологического характера (социально-профессиональная мобильность, ответственность, коммуникативность,

конструктивность, рефлексивность);

- включение студентов в ситуации, требующие многовариантного решения, а также моделирующие

возможные нестандартные производственные ситуации;

- соотнесенность учебно-технологической деятельности с реальной практикой профессиональной работы;
- использование коллективных форм деятельности, в которых благодаря групповой апперцепции происходит коррекция индивидуальных способов работы, а также усвоение профессиональнотехнологических эталонов и образцов;

- целостно-системное восприятия будущей профессиональной деятельности, которое способствует развитию мотивации углубления знаний.

Анализ научной литературы и собственные исследования позволили определить основные компоненты

показатели сформированности технологических навыков студентов при изучении общепрофессиональных дисциплин:

- мотивационный (побуждение студентов к производственно-технологической деятельности, выявление и закрепление мотивации учения путем постановки ближайших целей и задач);

- содержательный (освоение основного объема знаний и умений, составляющих основу общепрофессиональных дисциплин);

оценочно-результативный (степень эффективности работы студентов по овладению технологическим навыком, степень соответствия уровня подготовки квалификационным требованиям к выпускнику морского вуза).

В качестве показателей сформированности производственно-технологической компетентности выделили три уровня (низкий, средний, высокий).

Теоретически обосновав модель яхтенной деятельности в вузе, важно было экспериментально проверить степень эффективности ее влияния на условие формирования специальных технологических навыков будущих специалистов.

Результаты констатирующего эксперимента говорят о возможности организации в вузе такой среды, которая способствовала бы развитию профессионально-технологических навыков у студентов, побуждая их на занятия яхтингом и парусным спортом.

Опытно-экспериментальное исследование подтвердило, что наполнение предметов блока специальных и общепрофессиональных дисциплин смыслами яхтинга, а также введение спецкурса «Факультативные занятия яхтингом» и «Азбука яхтинга» для начинающих помогают студентам осознать и принять ценности яхтинга, приобрести новый профессиональный опыт взаимодействия в различных ситуациях.

Включая в педагогический процесс занятия яхтингом на факультативной основе, мы создаем среду, развивающую специальные технологические навыки студентов благодаря 
которой имитируется будущая профессиональнотехнологическая деятельность.

Проведенная работа подтверждает, что изменение характера содержания и организации учебных практик студентов углубляет и расширяет их технологические навыки, способствует приобретению и развитию нового субъектного опыта профессиональной деятельности.

Анализ результатов показал, что реализация всех трех педагогических условий (насыщение предметов блока специальных и общепрофессиональных дисциплин смыслами яхтинга; изменение характера содержания и организации учебных практик студентов; организация яхтенного сообщества единомышленников, объединенного общим смыслом, возможностью осуществлять социально значимую деятельность в вузе), приводит к позитивной динамике. $\mathrm{y}$ студентов занимающихся яхтингом гораздо быстрее, чем у их сверстников, происходят изменения в ценностных ориентациях студентов. Они проявляются в раннем (первый - второй курс) формировании у них специальных технологических навыков. У студентов старшего курса, углубленно занимающихся яхтингом, проявляется желание полноправно руководить студентами младших курсов в вопросах развития навыков управления движением яхтой по заданному курсу и настройкой парусов относительно ветра, счисления и обсервации своего места положения и прокладкой курса на бумажных картах, что развивает их будущие профессиональные навыки руководителя и офицера торгового флота.

Такие показатели критериев личностного развития студентов объясняются успешной реализацией педагогических условий, активизирующих процесс влияния яхтинга на личностное развитие будущих специалистов.

Результаты, подтверждают, что яхтинг является эффективной площадкой формирования специальных технологических навыков у студентов морских вузов.

Исследование не претендует на окончательное решение проблемы поиска путей и условий формирования специальных технологических навыков у студентов морских вузов, но актуализирует проблему подготовки специалиста, используя для этого ресурс занятий яхтингом в вузе. Дальнейшее углубленное исследование данной проблемы может осуществляться в направлении изучения влияния яхтинга на студентов, обучающихся по специальностям гуманитарного профиля.

Возможен научный поиск, направленный на разработку проблемы воспитания школьников, студенческой молодежи средних и специальных учебных заведений, а также учащихся профтехобразования по вовлечению их в занятия яхтингом, формированию у них активной гражданской позиции, любви к своему учебному заведению, к своей стране.

\section{References:}

1. Leontev A.N. (1975) Deyatelnost. Soznanie. Lichnost. M.: Politizdat, 1975 - 130 p.

2. Vygotskij L.S. (1934) Myshhlenie i rech. M.L.: Socekgiz, $1934-323$ p.

3. Galperin P.Ya. (1999) Vvedenie v psixologiyu. M.: Knizhnyj dom «Universitet», 1999 - 150 p.

4. Reshetova Z.A. (1985) Psixologicheskie osnovy professionalnogo obucheniya. M.: Iz-vo MGU, $1985-207$ p.

5. Talyzina N.F. (1998) Pedagogicheskaya psixologiya. M.: Akademiya, 1998 - 288 p.

6. Davydov V.V. (1992) Psixologicheskaya teoriya uchebnoj deyatelnosti i metodov nachalnogo obucheniya, osnovannyx na soderzhatelnom obobshhenii. T.: Peleng, $1992-$ $113 \mathrm{p}$.

7. Ilyasov I.I. (1981) Organizaciya sovmestnoj raboty studentov. (v soavt.). M.: $1981-145$ p.
8. Tixomirov O.K. (1975) Psixologicheskie issledovaniya tvorcheskoj deyatelnosti. M.: Nauka, 1975 - 252 p.

9. Asmolov A.G. (1984) Lichnost kak predmet psixologicheskogo issledovaniya. M.: Iz-vo MGU, 1984 - 104 p.

10. Samonenko Yu.A. (2001) Psixologiya i pedagogika. M.: Yuniti-Dana, 2001 - 277 p.

11. Mishchik S.A. (2015) Pedagogometrik - science and academic subject. Materialy Mezhdunarodnoy nauchnoy konferenctsii "European Technology in Science" 28.02.2015. ISJ Theoretical \& Applied Science 02 (22): 103-106 Malmö, Sweden. doi: http://dx.doi.org/10.15863/TAS.2015.02.22.17

12. Medvedev V.N. (2017) Yachting - is the factor of development of social activity of students. Isj theoretical \& applied science, 06 (50): 133-138. 
\begin{tabular}{l|lrl|l|ll} 
& ISRA (India) & $=\mathbf{1 . 3 4 4}$ & SIS (USA) & $=\mathbf{0 . 9 1 2}$ & ICV (Poland) & $=\mathbf{6 . 6 3 0}$ \\
Impact Factor: & ISI (Dubai, UAE) $=\mathbf{0 . 8 2 9}$ & PUHL (Russia) $=\mathbf{0 . 2 0 7}$ & PIF (India) & $=\mathbf{1 . 9 4 0}$ \\
& GIF (Australia) & $\mathbf{0 . 5 6 4}$ & ESJI (KZ) & $=3.860$ & IBI (India) & $=\mathbf{4 . 2 6 0}$ \\
& JIF & $\mathbf{1 . 5 0 0}$ & SJIF (Morocco) & $=\mathbf{2 . 0 3 1}$ & & \\
\hline
\end{tabular}

doi:

https://dx.doi.org/10.15863/TAS.2017.06.50.18

13. Medvedev V.N. (2017) Yachting - the condition of forming of the identity of the student. ISJ Theoretical \& Applied Science, 07
(51):
117-122.
doi:

https://dx.doi.org/10.15863/TAS.2017.07.51.20
14. Medvedev V.N. (2017) Yachting - development of the generalized professional activity of students. ISJ Theoretical \& Applied Science, 08 (52): 108-114. doi: https://dx.doi.org/10.15863/TAS.2017.08.52.17 